\section{Commentary: Paying it forward with concomitant tricuspid valve intervention - does a stitch in time really save lives?}

\author{
Sameer A. Hirji, MD, MPH, and \\ Tsuyoshi Kaneko, MD
}

The management of symptomatic tricuspid regurgitation (TR) remains controversial despite a class I recommendation for tricuspid valve (TV) surgery for severe TR at the time of left-sided valve surgery. ${ }^{1}$ Furthermore, these guidelines are primarily based on studies in patients undergoing mitral valve surgery rather than aortic valve replacement (AVR) because of the relative rarity of concurrent TR and aortic stenosis. ${ }^{2}$ Nonetheless, nationally, there is growing incidence of TV repairs ${ }^{3,4}$ largely due to concerns over TR progression and its prognostic significance on long-term survival., ${ }^{2,5}$

We read with great interest the article by Chancellor and colleagues $^{6}$ in this issue of the Journal. The authors used a regional, multicenter registry of more than 17,000 patients from 2001 to 2017 to examine the impact of existing TR with and without intervention during AVR. They found that approximately $7 \%$ of patients had at least moderate TR and concomitant TV intervention was infrequent, only performed in less than $1 \%$ of patients. The authors also surmised that increasing TR severity was associated with worse outcomes particularly with respect to morbidity. Although there were no significant differences in operative mortality between the TV intervention and no intervention cohorts, clinically, the operative mortality rate in the TV intervention group was 2-fold higher in the propensity-matched analysis.

The authors are to be congratulated for this insightful study, but there are several limitations that must be taken into account as we critically interpret the findings of this study. First, the sample size available for matching was

\footnotetext{
From the Division of Cardiac Surgery, Department of Surgery, Brigham and Women's Hospital, Harvard Medical School, Boston, Mass.

Disclosures: Kaneko is a consultant/speaker for Edwards Lifesciences, Medtronic, Abbott Structural Heart, Baylis Medical, and 4C Medical. Hirji has nothing to disclose with regard to commercial support.

Received for publication Feb 19, 2020; accepted for publication Feb 20, 2020; available ahead of print March 9, 2020.

Address for reprints: Tsuyoshi Kaneko, MD, Division of Cardiac Surgery, Brigham and Women's Hospital, 15 Francis St, Boston, MA 02115 (E-mail: tkaneko2@ bwh.harvard.edu).

J Thorac Cardiovasc Surg 2021;162:51-2

$0022-5223 / \$ 36.00$

Copyright (C) 2020 by The American Association for Thoracic Surgery

https://doi.org/10.1016/j.jtcvs.2020.02.096
}

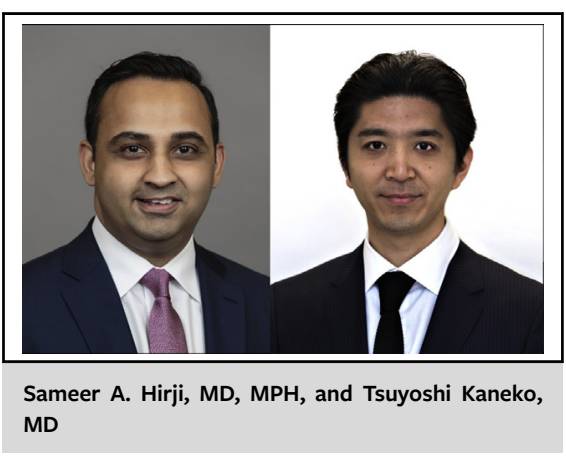

CENTRAL MESSAGE

Concomitant TV intervention at the time of AVR increases shortterm risk, but whether these risks are offset by the long-term benefit remains to be determined.

limited, and the study did not account for important clinical (eg, right ventricular dysfunction and presence of atrial fibrillation) and echocardiographic confounders (eg, tricuspid annular plane systolic excursion and TV annular diameter) in their risk-adjusted analysis. The second and biggest limitation, which the authors also acknowledged, was the lack of long-term data. In the context of mitral valve surgery, TV repair appears to be associated with improved survival in patients with concurrent TR and mitral regurgitation when long-term outcome was measured. ${ }^{7,8}$ Whether the same outcome is observed after concomitant AVR and TV surgery is not answered by this study.

Although the addition of TV intervention at the time of AVR increases patient and operative complexity, as the study demonstrates, the study findings raise a few important questions for future studies: First, is the presence and pathophysiology of concurrent TR at the time of AVR related to right ventricle dysfunction alone or closely interlinked to back pressure of aortic stenosis itself? Second, is the small price you pay with concomitant TV surgery justifiable in the long run? In other words, whether "a stitch in time" really saves lives remains to be determined until long-term survival data are available before we subject these patients to such a tour de force concomitant operation.

\section{References}

1. Nishimura RA, Otto CM, Bonow RO, Carabello BA, Erwin JP III, Fleisher LA, et al. 2017 AHA/ACC focused update of the 2014 AHA/ ACC guideline for the management of patients with valvular heart disease: a report of the American College of Cardiology/American Heart Association 
task force on clinical practice guidelines. J Am Coll Cardiol. 2017;70: 252-89.

2. Jeong DS, Sung K, Kim WS, Lee YT, Yang JH, Jun TG, et al. Fate of functional tricuspid regurgitation in aortic stenosis after aortic valve replacement. J Thorac Cardiovasc Surg. 2014;148:1328-33.e1.

3. Zack CJ, Fender EA, Chandrashekar P, Reddy YNV, Bennett CE, Stulak JM, et al. National trends and outcomes in isolated tricuspid valve surgery. J Am Coll Cardiol. 2017;70:2953-60.

4. Kilic A, Saha-Chaudhuri P, Rankin JS, Conte JV. Trends and outcomes of tricuspid valve surgery in North America: an analysis of more than 50,000 patients from the Society of Thoracic Surgeons database. Ann Thorac Surg. 2013;96:1546-52.
5. Nath J, Foster E, Heidenreich PA. Impact of tricuspid regurgitation on long-term survival. J Am Coll Cardiol. 2004;43:405-9.

6. Chancellor WZ, Mehaffey H, Belleter JP, Hawkins RB, Speir AM, Quader MA, et al. Impact of tricuspid regurgitation with and without repair during aortic valve replacement. J Thorac Cardiovasc Surg. 2021;162:44-50.e2.

7. Badhwar V, Rankin JS, He M, Jacobs JP, Furnary AP, Fazzalari FL, et al. Performing concomitant tricuspid valve repair at the time of mitral valve operations is not associated with increased operative mortality. Ann Thorac Surg. 2017;103:587-93.

8. Tang GH, David TE, Singh SK, Maganti MD, Armstrong S, Borger MA. Tricuspid valve repair with an annuloplasty ring results in improved long-term outcomes. Circulation. 2006;114:1577-81.
See Article page 44

\section{Commentary: Tricuspid regurgitation and aortic valve replacement: Act or observe?}

\author{
Siamak Mohammadi, MD, FRCSC, and \\ Dimitri Kalavrouziotis, MD, FRCSC
}

Multivalvular cardiac disease is a highly prevalent condition, for which cardiac surgeons need to have a clear strategy and fine-tune the operative approach to provide the best early and late clinical outcomes for their patients. The management of concomitant tricuspid regurgitation (TR) among patients with mitral valve disease has been fairly well studied, and current guidelines providing direction to the approach to TR in the presence of left-sided valve disease are largely based on data from patients with TR secondary to mitral valve pathology. However, the prevalence and clinical impact of TR, as well as the role of concomitant tricuspid valve (TV) intervention, in patients undergoing surgical aortic valve replacement (AVR) are not completely clear.

In this issue of the Journal, Chancellor and colleagues ${ }^{1}$ retrospectively analyze data from a multicentric cohort of 17,483 adult patients undergoing AVR with or without coronary artery bypass grafting among 19 institutions using the

From the Department of Cardiac Surgery, Quebec Heart and Lung Institute, Quebec City, Quebec, Canada.

Disclosures: Authors have nothing to disclose with regard to commercial support.

Received for publication Feb 27, 2020; accepted for publication Feb 28, 2020; available ahead of print March 9, 2020.

Address for reprints: Siamak Mohammadi, MD, FRCSC, Department of Cardiac Surgery, Quebec Heart and Lung Institute, 2725 Chemin Sainte-Foy, Quebec City, Quebec, Canada, G1V 4G5 (E-mail: siamak.mohammadi@fmed.ulaval.ca).

J Thorac Cardiovasc Surg 2021;162:52-4

$0022-5223 / \$ 36.00$

Copyright (c) 2020 by The American Association for Thoracic Surgery

https://doi.org/10.1016/j.jtcvs.2020.02.097
Check for updates

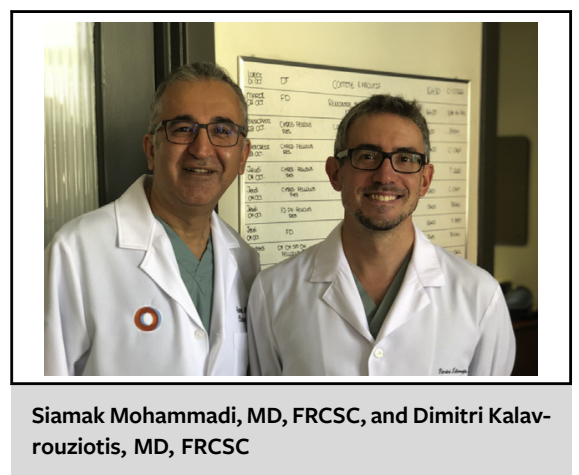

CENTRAL MESSAGE

TR portends a poor outcome after AVR. It remains unclear if correction of the TR improves early and late outcomes in AVR without mitral valve disease.

Society of Thoracic Surgeons database, excluding patients with mitral valve surgery. The prevalence of any TR was $49 \% \quad(\mathrm{n}=8499)$, and the majority of these patients $(85 \%)$ had mild TR. Moderate TR was noted in $6 \%$ of patients $(\mathrm{n}=1060)$, and severe TR was noted in $1 \%$ $(\mathrm{n}=187)$. Only 104 patients with various degrees of TR underwent TV surgery, and strikingly, less than one-third of patients with severe TR $(\mathrm{n}=58)$ underwent TV surgery at the time of AVR. It was not surprising that, in unadjusted comparisons, patients with TR had higher mortality and a higher composite major morbidity rate that was directly proportional to the severity of TR. TV surgery at the time of AVR did not appear to dampen the increased risk associated with TR, because mortality remained higher among those patients with concomitant AVR and TV surgery compared with those with isolated AVR, respectively, 